\title{
Improving Corrosion Resistance in Magnesium and its alloys
}

\author{
Md Rakibul Islam¹, Md Abdullah Al Mamun², Md Anwar Hossain ${ }^{3}$
}

CUMT, China

\begin{abstract}
The corrosion resistance of magnesium or magnesium parts depends on similar factors that are critical to other metals. However, because of the electrochemical activity of magnesium, the relative importance of some factors is greatly amplified. In this review, the corrosion characteristic of $\mathrm{Mg}$ and $\mathrm{Mg}$ alloys are described. Fundamental aspects of magnesium corrosion such as general corrosion, galvanic corrosion, pitting, and corrosion fatigue are reviewed. The factors that control the corrosion behaviour of $\mathrm{Mg}$ and $\mathrm{Mg}$ alloys are discussed in some detail. Finally, the more recently developed corrosion science and engineering underpinning various surface treatment methods such as electrochemical plating, conversion coating, anodising, gas-phase coating, organic coating, electrolytic plasma oxidation for magnesium alloys are described.
\end{abstract}

Keywords: Rust, Corrosion, Magnesium, Magnesium alloys, Iron rust.

\section{INTRODUCTION}

The need for fuel efficiency and increased performance in transportation systems continually places new demands on the materials used. The design criteria which automobile and aerospace industries are primarily concerned with are density, strength, stiffness, and corrosion resistance. Low-density materials may reduce fuel costs, increase range, and allow larger payloads. High strength and stiffness are necessary for adequate performance and safety characteristics, while corrosion resistance helps to ensure that design lifetime is achieved.

Magnesium is the $8^{\text {th }}$ most abundant element on the earth making up approximately $1.93 \%$ by mass of the earth's crust and $0.13 \%$ by mass of the oceans. Other advantages of magnesium alloys have played an important role in a broad variety of structural applications in the automobile, aerospace, electronics, and consumer products industries. Magnesium has specific high strength to weight ratio, and it is 35\% lighter than aluminium and 75\% lighter than iron. Typical magnesium alloys weigh $\sim 25 \%$ less than their aluminium counterparts at equal stiffness. Magnesium also has high thermal conductivity, good electromagnetic shielding characteristics, good ductility, excellent castability and better damping characteristics than aluminium, and $\mathrm{Mg}$ is easily recycled.

The main use of magnesium by far is as an alloying addition to aluminium alloys. Other major uses of magnesium include desulphurisation of steel and the production of ductile iron. As a structural material, it can be used in aerospace components, automobile and computer parts, mobile phones and sporting goods. Magnesium for structural applications is processed into castings (die, sand, permanent mold and investment), extrusions, forgings, impact extrusions and flat rolled products. Die castings account for $70 \%$ of the castings shipped. Magnesium can be joined by riveting, or any of the commonly used welding methods.

With the dramatically increased emphasis on weight reduction, magnesium is receiving a lot of attention as a material for use in the next generation automobiles. This is due to limited fossil fuel supplies and arising environmental problems associated with fuel emission products. Magnesium alloys are a promising alternative to the aluminium alloys currently dominating the transportation industry. However, the limited use of magnesium in engineering applications results mainly from the shortcomings including high reactivity in the molten state, inferior fatigue and creep properties compared to aluminium, poor corrosion and wear resistance.

One of the main challenges in the use of magnesium, particularly for outdoor application, is to overcome its poor corrosion resistance. Magnesium and its alloys are extremely susceptible to galvanic corrosion, which can cause severe attack in the metal resulting in decreased mechanical stability and an unattractive appearance. Corrosion can be minimised by the use of high purity alloys in which the heavy metal impurities such as iron, nickel and copper are kept below a threshold value. The elimination of bad design, surface contamination, galvanic couples and inadequate or incorrectly applied surface protection schemes can also significantly decrease the corrosion rate of magnesium alloys in service. 


\section{DOI: $10.17148 /$ IARJSET.2021.8218}

\section{Corrosion Characteristics Of PURE MAgnesium}

Magnesium, like most metals and alloys, relies on a natural surface film to control its corrosion. However, the nature of this film is not thoroughly understood. Good passive films are those that restrict the outward flow of cations, resist the inward flow of damaging anions or oxidants, and rapidly repair themselves in the event of localised breakdown. The structure and composition of the surface films, which depends strongly on environmental and metallurgical factors, such as electrolyte species and impurities in the metal, determine the protective ability of a passive film.

\section{Environmental effects}

No material shows high corrosion resistance in all kinds of environments. The high corrosion resistance of materials always refers to some specific environments. Magnesium has its own preferred service environments. However, there are fewer media that are suitable for the magnesium and magnesium alloys compared with other materials, such as steels and aluminium alloys. For example, magnesium and magnesium alloys are usually stable in basic solutions, but in neutral and acidic media they dissolve at high rates [3]. This is quite different from aluminium alloys that are normally stable in neutral media but are unstable in both basic and acidic solutions.

\section{General corrosion in aqueous solutions}

With few exceptions, there is no appreciable corrosion of pure magnesium near room temperature unless water is present. Magnesium dissolution in water or aqueous environments generally proceeds by an electrochemical reaction with water to produce magnesium hydroxide and hydrogen gas. Such a mechanism is relatively insensitive to the oxygen concentration, although the presence of oxygen is an important factor in atmospheric corrosion. Reaction 1 describes the probable overall reaction:

$$
\mathrm{Mg}+2 \mathrm{H}_{2} \mathrm{O}=\mathrm{Mg}(\mathrm{OH})_{2}+\mathrm{H}_{2}
$$

\section{E1}

This net reaction can be expressed as the sum of the following partial reactions:

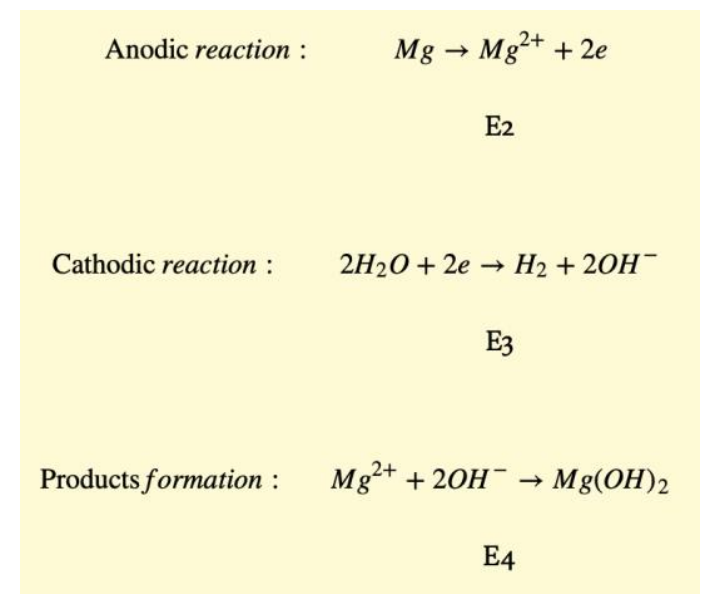

The reduction process of hydrogen ions and the hydrogen over voltage of the cathode play an important role in the corrosion of $\mathrm{Mg}$. Low over voltage cathodes facilitate hydrogen evolution, causing a substantial corrosion rate.

Fig. 1 shows the corrosion domains of $\mathrm{Mg}$ in the $\mathrm{Mg}-\mathrm{H}_{2} \mathrm{O}$ system. The region of water stability lies between the line a and line $\mathrm{b}$. At a potential below line a, hydrogen is evolved; above line b, oxygen is evolved. The numbers identify the reactions that separate the different phases shown in reactions 5, 6, and 7. The horizontal and vertical parallel lines for reactions 5 and 6 give the concentration of $\mathrm{Mg}^{2+}$ in $\mathrm{mol}^{-1}$ as a power of 10 . As shown in Fig. 1, the ringed numbered lines separate the regions of corrosion (dissolved cations, e.g. $\mathrm{Mg}^{2+}$ ), immunity (unreacted metal, $\mathrm{Mg}$ ), and passivation (corrosion products, $\mathrm{Mg}(\mathrm{OH})_{2}$ ). From Fig. 1, it can be seen that stable films would be expected to form depending on the values of the potential and $\mathrm{pH}$. In neutral and alkaline environments, the magnesium hydroxide product can form a surface 


\section{DOI: $10.17148 /$ IARJSET.2021.8218}

film that offers considerable corrosion protection to the pure magnesium or its common alloys, although this is not as effective as the oxide layer formed on aluminium. As corrosion proceeds, the metal surface experiences a local $\mathrm{pH}$ increase because of the formation of $\mathrm{Mg}(\mathrm{OH})_{2}$, whose equilibrium $\mathrm{pH}$ is about 11 . The protection supplied by this film is therefore highly dependent on the condition of exposure. High purity magnesium is reported to have a corrosion rate of $10^{-2}-10^{-3}$ mils per year (mpy) when exposed to 2 normal $\mathrm{KOH}$ solutions at $25{ }^{\circ} \mathrm{C}$

$$
\begin{array}{r}
\text { Linea : } 2 \mathrm{H}^{+}+2 e \rightarrow \mathrm{H}_{2} \\
\text { Lineb: } 4 \mathrm{OH}^{-}-4 e \rightarrow \mathrm{O}_{2}+\mathrm{H}_{2} \mathrm{O} \\
\text { 1. } \mathrm{Mg}+2 \mathrm{H}_{2} \mathrm{O}=\mathrm{Mg}(\mathrm{OH})_{2}+\mathrm{H}_{2}
\end{array}
$$

2. $\mathrm{Mg}^{2+}+\mathrm{H}_{2} \mathrm{O}=\mathrm{MgO}+2 \mathrm{H}^{+}$

E6

3. $M g=M g^{2+}+2 e$

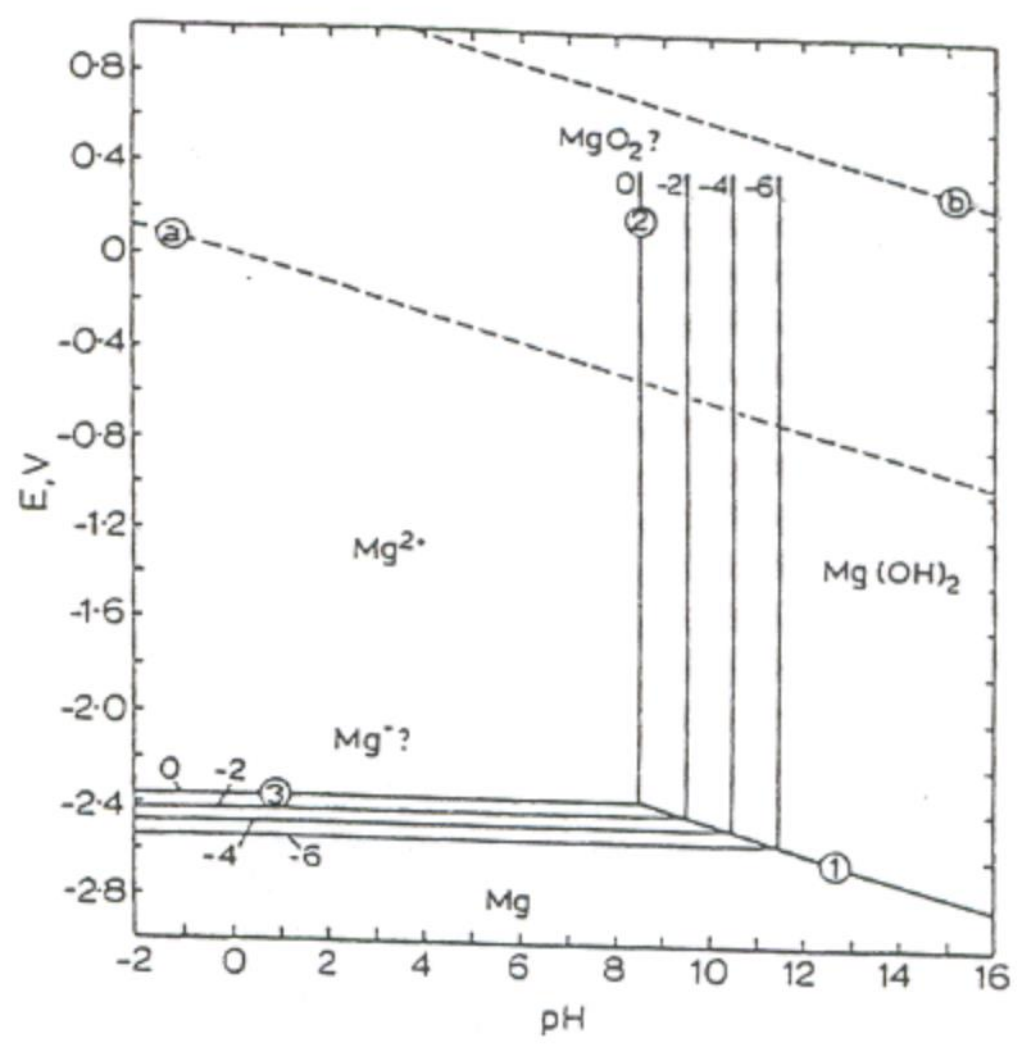

Figure 1 Electrochemical potential-pH equilibrium diagram for the magnesium-water system at $25^{\circ} \mathrm{C}$

Magnesium's corrosion performance in pure water is strongly dependent on temperature. At elevated temperatures, the resistance to corrosion in water decreases with increasing temperature, corrosion becoming particularly severe above $100^{\circ} \mathrm{C}$. 


\section{DOI: $10.17148 /$ IARJSET.2021.8218}

Magnesium is subject to dissolution by most acids. Even in dilute solutions of strong and moderately weak acids, magnesium dissolves rapidly. There are a few exceptions, such as chromic acid and hydrofluoric acid. Very slow dissolution of magnesium in chromic acid is due to its becoming passive in this acid. An insoluble surface film of $\mathrm{MgF}_{2}$ is formed which protects against further attack, is the reason why magnesium is resistant to hydrofluoric acid.

The strong alkalinity of the natural hydroxide film on magnesium means there is little tendency for the compound to give up a proton to strong alkalis; consequently, the film provides excellent protection even in strong hot alkali solutions that would readily attack aluminium or zinc alloys. Magnesium's resistance to alkali attack combined with the metal's lightweight has made it the preferred material for cement finishing tools for many years

\section{Metallurgical Effects}

Magnesium becomes susceptible to accelerated corrosion if there are significant impurity levels present or it is in contact with other metals. Due to the lack of a nature surface film on the impurities, the more positive potential allows impurities to be efficient cathodes for hydrogen discharge, thereby providing significant micro galvanic acceleration off the corrosion rate. Therefore even small amount of impurities in pure magnesium with metals having low hydrogen over voltages, such as $\mathrm{Fe}, \mathrm{Ni}, \mathrm{Co}$, or $\mathrm{Cu}$, drastically reduces its corrosion resistance. Metals with higher hydrogen over voltages, such as lead, zinc, and cadmium, and also strongly electronegative metals, such as manganese and aluminium, are less dangerous in this respect. Fig. 2 shows effect of impurity and alloying elements on the corrosion of magnesium in a $3 \% \mathrm{NaCl}$ solution at room temperature. $\mathrm{Fe}, \mathrm{Cu}, \mathrm{Ni}$ can increase the corrosion rate, while $\mathrm{Cd}, \mathrm{Pb}, \mathrm{Sn}$, and $\mathrm{Al} \mathrm{can}$ drastically reduce the corrosion resistance of pure magnesium.

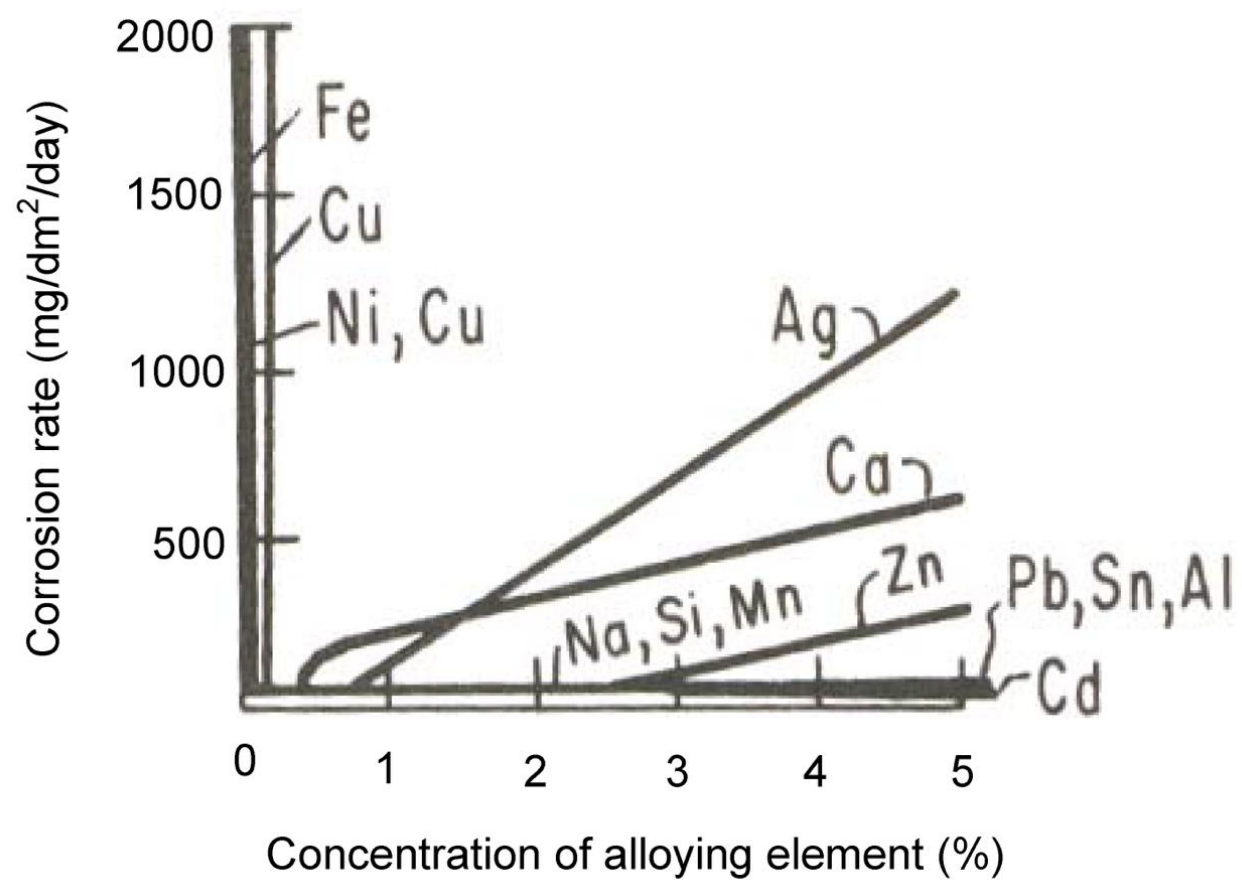

Figure 2 .

Effect of impurity and alloying elements on corrosion of magnesium (all alloys are formed by magnesium and the given element) in $3 \% \mathrm{NaCl}$ solution at room temperature

\section{Corrosion Characteristic of Mg alloys.}

Magnesium alloys in general can be divided into two main groups: (1) those containing aluminium as the primary alloying element; and (2) those free of aluminium and containing small additions of zirconium for the purpose of grain refinement. The most widely used magnesium alloys are those with aluminium (to $10 \%$ ), zinc (to $3 \%$ ), and manganese (to $2.5 \%$ ). It is desirable that other metals, particularly $\mathrm{Fe}, \mathrm{Cu}, \mathrm{Ni}$ and $\mathrm{Si}$ be present in very small amounts not exceeding a total of $0.4 \%$ to $0.6 \%$. Mg alloys corrosion is governed by the characteristics of its surface film. The properties of film on $\mathrm{Mg}$ alloys depend on $\mathrm{Mg}$ alloys' metallurgy and environmental factors. Magnesium metallurgy includes alloying and impurity elements, phase components and microstructure. Metallurgical manipulation can provide an effective means to 


\section{International Advanced Research Journal in Science, Engineering and Technology}

Vol. 8, Issue 2, February 2021

\section{DOI: $10.17148 / I A R J S E T .2021 .8218$}

improve the corrosion resistance of magnesium alloys.

The most critical factor in the corrosion behaviour of $\mathrm{Mg}$ and $\mathrm{Mg}$ alloys is the metal purity. Iron, nickel, and copper are extremely deleterious because they have low solid-solubility limits and provide active cathodic sites which lead to galvanic corrosion and increase corrosion rates. At the same concentration, the detrimental effect of these elements decreases as follows: $\mathrm{Ni}>\mathrm{Fe}>\mathrm{Cu}$. When the impurity concentration exceeds the tolerance limit, the corrosion rate is greatly accelerated, whereas the corrosion rate is low when the impurity concentration is lower than the tolerance limit. The tolerance limits in magnesium alloys are influenced by the presence of other elements. For example, the iron tolerance limit for magnesium-aluminium alloys depends on the $\mathrm{Mn}$ or $\mathrm{Zn}$ concentration. Furthermore, impurity limits are different depending on the method of manufacture. For example, die cast AZ91 has higher nickel tolerance than gravity cast AZ91. And the slower solidification rates significantly affect the nickel tolerance, but not $\mathrm{Fe}$ and $\mathrm{Cu}$. Different alloys have different tolerance limits as summarised in Table 1. In Table 1, the impurity tolerance limit of 0.032 Mn actually means that if there is manganese in a magnesium alloy, then the alloy would be able to tolerate an amount of the iron impurity equal to 0.032 of the manganese concentration (by weight).

\begin{tabular}{|c|c|c|c|c|}
\hline \multirow[b]{2}{*}{ Specimen } & \multirow[b]{2}{*}{ Condition } & \multicolumn{3}{|c|}{ Tolerance Limits* } \\
\hline & & $\mathbf{F e}$ & $\mathbf{N i}$ & $\mathbf{C u}$ \\
\hline Pure Mg & & $170 \mathrm{ppm}$ & $5 \mathrm{ppm}$ & $1000 \mathrm{ppm}$ \\
\hline Pure Mg & & $170 \mathrm{ppm}$ & $5 \mathrm{ppm}$ & $1300 \mathrm{ppm}$ \\
\hline $\mathrm{AZ}_{91}$ & & $20 \mathrm{ppm}$ & $12 \mathrm{ppm}$ & $900 \mathrm{ppm}$ \\
\hline $\mathrm{AZ}_{91}$ & & $0.032 \mathrm{Mn}$ & $50 \mathrm{ppm}$ & $400 \mathrm{ppm}$ \\
\hline $\mathrm{AZ}_{91}$ & High pressure $(\mathrm{F})$ & $0.032 \mathrm{Mn}$ & $50 \mathrm{ppm}$ & $400 \mathrm{ppm}$ \\
\hline $\mathrm{AZ}_{91}$ & Low pressure $(\mathrm{F})$ & $0.032 \mathrm{Mn}$ & $10 \mathrm{ppm}$ & $400 \mathrm{ppm}$ \\
\hline $\mathrm{AZ}_{91}$ & Low pressure $\left(\mathrm{T}_{4}\right)$ & $0.035 \mathrm{Mn}$ & $10 \mathrm{ppm}$ & $100 \mathrm{ppm}$ \\
\hline AZ91 & Low pressure (T6) & $0.046 \mathrm{Mn}$ & $10 \mathrm{ppm}$ & $400 \mathrm{ppm}$ \\
\hline $\mathrm{AZ}_{91 \mathrm{~B}}$ & & & $<100$ ppm & $<2500 \mathrm{ppm}$ \\
\hline $\mathrm{AS}_{41}$ & Die casting & $0.032 \mathrm{Mn}$ & $50 \mathrm{ppm}$ & $400 \mathrm{ppm}$ \\
\hline AZ91 $_{91}$ & Die casting & $50 \mathrm{ppm}$ & $50 \mathrm{ppm}$ & $700 \mathrm{ppm}$ \\
\hline $\mathrm{AZ}_{91}$ & Die casting & $0.032 \mathrm{Mn}$ & $50 \mathrm{ppm}$ & $700 \mathrm{ppm}$ \\
\hline $\mathrm{AZ}_{91}$ & Gravity casting & $0.032 \mathrm{Mn}$ & $10 \mathrm{ppm}$ & $400 \mathrm{ppm}$ \\
\hline AM6o & Die casting & $0.021 \mathrm{Mn}$ & $30 \mathrm{ppm}$ & $10 \mathrm{ppm}$ \\
\hline $\mathrm{AE}_{42}$ & & $0.01 \mathrm{Mn}$ & $40 \mathrm{ppm}$ & $200 \mathrm{ppm}$ \\
\hline
\end{tabular}

\section{Galvanic}

When two dissimilar metals are placed in contact in a corrosive or conductive solution, a potential difference produces electron flow between them. The more active metal then becomes anodic and is corroded, and the less active metal becomes cathodic and is protected. This kind of corrosion is called galvanic corrosion, or two-metal corrosion. Magnesium and its alloys are highly susceptible to galvanic corrosion, because magnesium has the lowest standard potential of all the engineering metals.

Galvanic corrosion can also occur between two different phases. When magnesium and its alloys are placed contact with other metals, magnesium and magnesium alloys are corroded, while hydrogen gas is evolved on the other metals. When magnesium and magnesium alloys contain second phases because of impurities or alloying elements, the matrix $\alpha-$ phase is corroded, while the hydrogen gas is evolved on the second phases.

\section{Corrosion Fatigue}

There is very little research on the corrosion fatigue of magnesium alloys. Corrosion fatigue has a close relationship with humidity. For example, AZ31 subjected to an axial load cycle at $10^{5}$ cycles per hour in air and then subjected to increasing 


\section{International Advanced Research Journal in Science, Engineering and Technology}

Vol. 8, Issue 2, February 2021

\section{DOI: $10.17148 / I A R J S E T .2021 .8218$}

levels of humidity showed a slow decrease in the fatigue strength once the humidity exceeded 50\%. At $93 \%$ relative humidity, the measured fatigue strength had declined to about $75 \%$ of that in dry air. It has also been found that corrosion fatigue cracks propagate in a mixed transgranular-intergranular mode and that the corrosion fatigue crack growth rate was accelerated by the same environments that accelerate stress corrosion crack growth. And the corrosion fatigue resistance of AZ91-T6 was significantly reduced in 3.5\% salt water relative to that in air.

\section{Pitting Corrosion}

Few studies have addressed these forms of localised attack of $\mathrm{Mg}$ and $\mathrm{Mg}$ alloys because other forms of corrosion such as general, galvanic, or stress corrosion have been the cause of more serious failure of these materials. The studies of pitting of $\mathrm{Mg}$ and $\mathrm{Mg}$ alloys have been concerned with comparing the pitting behaviour of cast too that of rapidly solidified Mg alloys. Makar and Kruger showed that rapidly solidified AZ61 exhibited better resistance to pitting than cast AZ61 in a buffered carbonate solution containing various levels of $\mathrm{Cl}^{-}$. Pit initiation of rapidly solidified AZ61 is found to take place at a higher potential and the pit growth rate was apparently lower than cast AZ61. In a review given by Makar and Kruger, it is reviewed that the difference between rapidly solidified and cast $\mathrm{Mg}$. A metallic glass $\mathrm{Mg}_{70} \mathrm{Zn}_{30}$ exhibited a better resistance to pitting. Also, the film on the metallic glass was more protective against pitting attack than the pure $\mathrm{Mg}$. The glassy $\mathrm{Mg}$ alloy is found to exhibit a more stable passive film than pure $\mathrm{Mg}$, $\mathrm{Zn}$ or several other crystalline Mg-based alloys. Heavy metal contamination promotes general pitting attack. In Mg-Al alloys, pits are often formed due to selective attack along $\mathrm{Mg}_{17} \mathrm{Al}_{12}$ network that is followed by the undercutting and falling out of grains. Crevice corrosion does not occur with the $\mathrm{Mg}$ alloys because corrosion is relatively insensitive to oxygen concentration difference.

\section{III.Corrosion Prevention}

There are a number of approaches to overcoming the corrosion problems of $\mathrm{Mg}$ alloys:

(1) High purity or new alloys: Decrease impurities to below their tolerance limits and develop new alloys with new elements, phases, and microstructure distributions;

(2) Surface modification: this includes ion implantation and laser annealing;

(3) Refinement of the grain size and intermetallic particles: corrosion resistance can be affected through the microstructure;

(4) Protective films and coatings.

Improving corrosion resistance by producing $\mathrm{Mg}$ alloys with low concentration of deleterious elements is an often-used strategy. This ensures the highest possible degree of uniform corrosion resistance of the starting material There are two main surface modification techniques which are discussed below.

Ion implantation is the technique whereby almost any elemental ions may be implanted into the surface of any solid using a beam of energetic ions accelerated into a target under vacuum conditions. This homogenisation is the primary benefit of ion implantation in terms of corrosion resistance. Additional benefits include the ability to alter the surface while retaining the bulk properties, the creation of novel surface alloys, and the elimination of surface adhesion problems associated with coatings. The primary disadvantages are that it is a line-of-sight technique and it modifies only a thin film. Akvipat and co-workers examined the effects of iron implanted $\mathrm{Mg}$ and AZ91C in boric acid and borate buffer solution with $1000 \mathrm{ppm} \mathrm{NaCl}$. It was known that iron degrades the corrosion resistance of magnesium alloys when introduced during conventional processing, and the goal of their work was to evaluate the effects of iron introduced by implantation. The implanted iron changed the nature of the attack on the $\mathrm{AZ} 91$. In the un-implanted case, $\mathrm{Mg}_{17} \mathrm{Al}_{12}$ islands acted as local cathodes, causing accelerated corrosion of the surrounding matrix to form a deep channel around these islands. The implanted iron shifted the attack to the $\mathrm{Mg}_{17} \mathrm{Al}_{12}$ particles themselves, which resulted in a more uniform attack without the rapid channelling suffered by the magnesium matrix in the un-implanted case. The results of these ion implantation studies are encouraging, but improvements in the economics and versatility of the implantation process are necessary for increasing the practical importance of this approach.

Laser annealing technique involves the formation of metastable solid solutions as promoted at metal surfaces by laser annealing, where cooling rates as high as $1010 \mathrm{~K} / \mathrm{s}$ are achievable using lasers pulsed in the nanosecond range. It is, therefore, another form of rapid solidification processing, but involves the melting and solidification of surface layers only. Besides the advantages of ion implantation, the advantages include the ability of lasers to treat more complex geometries, the greater depth of treatment, inexpensive operation costs, and greater control of the concentration of the modified layer. The main disadvantage is the extra machining necessary because of dimensional changes during treatment. Akvipat and co-workers examined the effects of thin layers of about $100 \mathrm{~nm}$ of $\mathrm{Al}, \mathrm{Cr}, \mathrm{Cu}, \mathrm{Fe}$, and $\mathrm{Ni}$ on the pitting resistance of $\mathrm{AZ91C}$ in boric acid-borate solution with $1000 \mathrm{ppm} \mathrm{NaCl}$. The role-played by these elements after 


\section{International Advanced Research Journal in Science, Engineering and Technology}

Vol. 8, Issue 2, February 2021

\section{DOI: 10.17148/IARJSET.2021.8218}

laser treatment is certainly different from that when they are present in conventional processing, especially $\mathrm{Cu}, \mathrm{Fe}$, and $\mathrm{Ni}$, which are detrimental, even in small concentrations under equilibrium conditions. This improvement is probably related to the structure and composition of the near-surface region

Heat-treatment can drastically alter the size, amount and distribution of the precipitated $\beta$ phase, $\operatorname{Mg}_{17} \mathrm{Al}_{12}$, which in turn, alters the corrosion behaviour of Mg-Al alloys. Aung and Zhou studied an AZ91D ingot in the as-cast condition that was homogenised by solution treatment and then aged for various periods of time. The homogenisation treatment of an AZ91D ingot at $420{ }^{\circ} \mathrm{C}$ for $24 \mathrm{~h}$ was found to be effective in dissolving the $\beta$-precipitates. Artificial ageing at $200^{\circ} \mathrm{C}$ caused precipitation of the $\beta$-phase mainly along the grain boundaries. The volume fraction of the $\beta$-phase was observed to increase with ageing time. A homogenisation treatment improved the corrosion resistance of the AZ91D ingot, but ageing for $8 \mathrm{~h}, 16 \mathrm{~h}$ or $26 \mathrm{~h}$ lowered the corrosion resistance. These results support the suggestion that micro-galvanic coupling exists between the cathodic $\beta$-phase and the anodic $\alpha$-matrix. The inhibiting effect of the $\beta$-phase in the artificially aged alloy predominated during the short interval of electrochemical testing but the accelerating effect of the decrease in aluminium content in the matrix predominated in the long period immersion testing. During immersion testing, the $\beta$ phase may dissolve into the chemical solution and this also tends to accelerate the corrosion rate.

There are a number of technologies available for coating magnesium and its alloys. These include electrochemical plating, conversion coatings, anodising, hydride coatings, organic coatings and vapour-phase processes.

One of the most cost effective and simple techniques for introducing a metallic coating to a substrate is by electrochemical plating. The electrochemical plating can be subdivided into two types: electroplating and electroless plating. In both cases a metal salt in solution is reduced to its metallic form on the surface of the substrates. In electroplating the electrons for reduction are supplied from an external source. In electroless or chemical plating the reducing electrons are supplied by a chemical reducing agent in solution or, in the case of immersion plating, the substrate itself.

Electroplating, Besides some traditional disadvantages of electroplating such as non-uniform coatings and difficulties in coating complex shapes, there are some challenges to be met for electroplating on magnesium. The pre-treatment processes are complicated due to the fact that, in the presence of air, magnesium very quickly forms a passive oxide layer. $\mathrm{Cu}-\mathrm{Ni}-\mathrm{Cr}$ plating has been shown to have good corrosion resistance in interior and mild exterior environments. Also, it is necessary to develop non-traditional plating baths since magnesium reacts violently with most acids and dissolves in acidic media. Furthermore, magnesium and its alloys are prone to galvanic corrosion, so the metal coating must be pore free otherwise the corrosion rate will increase. Usually, the coating is at least $40-50 \mu \mathrm{m}$ thick to ensure pore-free coatings. Furthermore, the alloys are difficult to plate because intermetallic species such as $\mathrm{Mg}_{\mathrm{x}} \mathrm{Al}_{\mathrm{y}}$ are formed at the grain boundaries, resulting in a non-uniform surface potential across the substrate, and therefore further complicating the plating process. Recently, Jiang et al studied Zn-Ni alloy coatings pulsed-plated on magnesium alloy AZ91. Before deposition, the substrate surfaces were processed in a standard industrial way: polishing with alumina sand paper, alkaline degreasing, chemical pickling, activation, zinc immersion and $\mathrm{Zn}-\mathrm{Cu}$ alloy plating. A Zn layer and a Zn$\mathrm{Cu}$ layer under the $\mathrm{Zn}-\mathrm{Ni}$ coating were applied to improve the adhesion and to protect the substrate using the small electrode potential difference between $\mathrm{Zn}-\mathrm{Cu}$ and $\mathrm{Zn}-\mathrm{Ni}$ layer. $\mathrm{Zn}-\mathrm{Ni}$ coatings were deposited in an alkaline bath with a composition as $\mathrm{ZnO} 10 \mathrm{~g} / \mathrm{l}, \mathrm{NaOH} 150 \mathrm{~g} / \mathrm{l}, \mathrm{NiSO}_{4} \bullet 6 \mathrm{H}_{2} \mathrm{O} \mathrm{g} / \mathrm{l}$, triethanolamine $50 \mathrm{~g} / \mathrm{l}$, and at $10-40^{\circ} \mathrm{C}, 500-4000 \mathrm{~Hz}, 0.04-$ $0.1 \mathrm{~A} / \mathrm{cm}^{2}$. The bonding strength can be as high as $14.8 \mathrm{MPa}$. The corrosion life of the Zn-Ni coating can reach over 200 $\mathrm{h}$ in a salt spray test conducted according to ASTM B1117. However, no detailed data were given on the porosity of the coatings, which may increase the corrosion rate due to the galvanic corrosion effect.

Electroless plating has good throwing power and can produce a uniform coating thickness on complex objects. It also involves a simple pre-treatment and is suitable for magnesium alloys with high aluminium contents. However, electroless deposited coatings cannot be too thick, the bath life is limited, and deposition rates are slow. In particular, electroless plating requires the use of hydrofluoric acid during the pre-treatment, which increases the danger of the operation and is not environmentally friendly. Research on increasing the bath life and eliminating toxic chemicals is necessary in order to create a green-plating process for coating magnesium. Sharma et al. studied the properties of an electroless nickel coating on magnesium alloy ZM21. The solution contains nickel carbonate, sodium hypophosphite (metal-reducing agent), citric acid and bifluoride (act as accelerators, complexing agent, and accelerators), thiourea (solution stabilizer and brightening agent) and ammonia solution. The paper put forward some reactions, and suggested that the autocatalytic reaction for nickel deposition is initiated by catalytic dehydrogenation of the reducing agent with release of hydride ion, which then supplies electrons for the reduction of nickel ions.

The coated samples were immersed in a 5\% solution of sodium chloride at $\mathrm{pH} 7.0$. No corrosion spots on the coatings were noticed after $96 \mathrm{hrs}$ of immersion. The formation of corrosion spots initiated only after the fifth day of immersion. Recently, Huo et al. developed an environmental-friendly combined technique of chemical conversion treatment followed 


\section{International Advanced Research Journal in Science, Engineering and Technology}

Vol. 8, Issue 2, February 2021

\section{DOI: $10.17148 / I A R J S E T .2021 .8218$}

by electroless nickel plating for AZ91D alloy to improve corrosion resistance. The presence of the conversion coating, which was mainly $\mathrm{MgSnO}_{3} \cdot \mathrm{H}_{2} \mathrm{O}$, between the nickel coating and the substrate reduced the potential difference and avoided any catastrophic galvanic corrosion between nickel and magnesium. The electroless nickel coating containing about $10 \mathrm{wt} \%$ phosphorus greatly enhanced the corrosion potential of AZ91D from $-1.50 \mathrm{~V}$ to- $0.60 \mathrm{~V}$.

Phosphate-permanganate treatments are being explored as an alternative to conventional chromate conversion coatings. These treatments are more environmentally friendly and have been shown to have corrosion resistance comparable to chromate treatments.

Chong and Shih reported that a conversion coating on magnesium alloys AZ61A, AZ80A and AZ91D prepared from a solution containing permanganate $\left(\mathrm{KMnO}_{4} 20 \mathrm{~g} / \mathrm{l}\right)$ and phosphate $\left(\mathrm{MnHPO}_{4} 60 \mathrm{~g} / \mathrm{l}\right)$ showed an equivalent or slightly better passive capability than a conventional chromate-based conversion treatment, but an inferior passive capability for the pure Mg specimen. Hawke and Albright studied a phosphate-permanganate treatment for the conversion coating of AM60B. The coating is based on magnesium phosphate, but contains significant amounts of aluminium compounds generated from the alloy's aluminium content, and manganese compounds formed by reduction of the permanganate ion. The manganese is considered to contribute manganese to the coating, and acts as an accelerator without depositing metallic manganese on the magnesium surface. The coatings were shown to have good corrosion resistance and paint adhesion.

It was found that the most important factor in producing the best quality conversion coatings was the control of the $\mathrm{pH}$. Since $\mathrm{pH}$ is the most important factor determining conversion coating quality, the research on stabilising the $\mathrm{pH}$ of solutions has gained increasing attention. Umehara et al. claimed that a $\mathrm{pH}$-stabilising solution was developed for the conversion coating on AZ91D. The surface film formed was composed of magnesium oxide, and manganese oxide, and contained boron oxide. The $\mathrm{pH}$ change was insignificant with increasing the surface area of the magnesium treated. After cleaning and surface activation, the samples were immersed in a solution containing potassium permanganate and either nitric or hydrofluoric acid. The coatings formed in the bath containing nitric acid were substantially thicker and crystalline manganese oxide was observed. The corrosion resistance of these coatings was equivalent to the protection afforded by a standard chromate treatment.

\section{IV.CONCLUSION}

The examples described in the previous section demonstrate that it is possible to develop appropriate coating schemes for the protection of magnesium for use in automotive components. However, no single coating technology has been developed which functions to adequately protect magnesium from corrosion in harsh service conditions. For example, in winter, the mixture of deicing salt and sand often attacks $\mathrm{Mg}$ chassis components of automobiles, such as transfer cases. Also, coolants can cause corrosion on $\mathrm{Mg}$ alloy engine blocks.

One of the most effective ways to prevent corrosion is to coat the base material. In order for a coating to provide adequate corrosion protection for $\mathrm{Mg}$ and $\mathrm{Mg}$ alloys, the coating must be uniform, pore free, well adhered, and self-healing in case that physical damage to the coating may occur.

In the case of electrochemical plating, the capital investment is relatively small. Electroplating process is extremely difficult to achieve uniform coatings on complex shapes due to uneven throwing power. Electroless plating can obtain uniform coatings. However, there are some serious concerns over waste disposal.

Conversion coatings also represent a minimum capital investment, however the most widely used type of conversion coatings are chromate conversion coatings. These represent a serious environmental risk due to the presence of leachable hexavalent chromium in the coatings. A number of chromate free conversion coatings are under development but this technology is still in its infancy. Conversion coatings do not provide adequate corrosion and wear protection from harsh service conditions when used alone. However, they can act as a good base for producing adherent organic coatings and act to enhance corrosion resistance of a combined coating system by protecting the substrate at the defect sites in overlying layers.

Anodising is the most widely commercially used coating technology for magnesium and its alloys. This process is technologically more complex than electroplating or conversion coating but is less sensitive to the type of alloy being coated. It does involve more capital investment due to the need for cooling systems and high power consumption but this may be balanced by the decreased cost of waste disposal. The coatings produced by anodising are porous ceramic-like coatings. These properties impart good paint-adhesion characteristics and excellent wear and abrasion resistance to the 


\section{International Advanced Research Journal in Science, Engineering and Technology}

Vol. 8, Issue 2, February 2021

\section{DOI: 10.17148/IARJSET.2021.8218}

coating. However, without further sealing, they are not adequate for use in applications where corrosion resistance is of primary importance.

The use of gas-phase coating processes and laser surface melting to modify the surface or create coatings is an excellent alternative for corrosion protection of $\mathrm{Mg}$ alloys with little environmental impact. However, the capital investment of equipment is really high.

Organic coatings such as sol-gel coatings on magnesium alloys require a minimum of pre-treatment steps prior to deposition. But, their thicknesses might be limited.

It is evident that there is limited information comparing erosion and corrosion properties of the ceramic coatings prepared from different electrolytes. The relative significance of the EPO process parameters on effects of the corrosion resistance of magnesium alloys, in particular for bio-applications, needs to be fully investigated.

\section{REFERENCES}

1. Henry Hu, Xueyuan Nie and Yueyu Ma (November 5th 2014). Corrosion and Surface Treatment of Magnesium Alloys, Magnesium Alloys Properties in Solid and Liquid States, Frank Czerwinski, IntechOpen, DOI: 10.5772/58929. Available from: https://www.intechopen.com/books/magnesium-alloys-properties-in-solid-and-liquid-states/corrosion-and-surface-treatment-of-magnesiumalloys

2. J.X. Jia, A. Atrens, G. Song, T.H. Muster, Simulation of galvanic corrosion of magnesium coupled to a steel fastener in NaCl solution, Materials and Corrosion 56 (2005) 468.

3. Jimmy X. Jia, Guangling Song, Andrej Atrens, Influence of geometry on galvanic corrosion of AZ91D coupled to steel, Corrosion Science 48 (2006) 2133.

4. K. Jafarzadeh, T. Shahrabi, M.G. Hosseini, EIS study on pitting corrosion of AA5083-H321 Aluminum-Magnesium alloy in stagnant 3.5\% NaCl Solution, Journal of Materials Science and Technology 24 (2008) 215.

5. Susanne Bender, Joachim Goellner, Andrej Atrens, Corrosion of AZ91 in $1 \mathrm{~N} \mathrm{NaCl}$ and the mechanism of magnesium corrosion, Advanced Engineering Materials 10 (2008) 583.

6. Guangling Song, Andrej Atrens, Xianliang Wu, Bo Zhang, Corrosion behaviour of AZ10nAZ490 and AZ80 in sodium chloride, Corrosion Science 40 (1998) 1769-1791.

7. M.F. Horstemeyer, N. Yang, Ken Gall, D.L. McDowell, J. Fan, P.M. Gullett, High cycle fatigue of a die cast AZ91E-T4 magnesium alloy, Acta Materialia 52 (2004) 1327-1336.

8. Andrej Atrens, Wolfgang Dietzel, The negative difference effect and unipositive Mg+, Advanced Engineering Materials 9 (2007) 292.

9. I. Apachitei, L.E. Fratila-Apachitei, J. Duszczyk, Microgalvanic activity of an Mg-Al-Ca-based alloy studied by scanning Kelvin probe force microscopy, Scripta Materialia 57 (2007) 1012-1015.

10. Andrey Shkurankov, Sherif Zein El Abedin, Frank Endres, AFM-Assisted investigation of the corrosion behaviour of magnesium and AZ91 alloys in an ionic liquid with varying water content, Australian Journal of Chemistry 60 (2007) 35-42.

11. Rajan Ambat, Naing Naing Aung, W. Zhou, Evaluation of microstructural effects on corrosion behaviour of AZ91D magnesium alloy, Corrosion Science 42 (2000) 1433.

12. J. Warkus, M. Raupach, J. Gulikers, Numerical modelling of corrosion - Theoretical backgrounds, Materials and Corrosion 57 (2006) 614.

13. Guangling Song, Andrej Atrens, Understanding magnesium corrosion-A framework for improved alloy performance, Advanced Engineering Materials 5 (2003) 837.

14. J.W. Chang, L.M. Peng, X.W. Guo, A. Atrens, P.H. Fu, W.J. Ding, X.S. Wang, Comparison of the corrosion behaviour in 5\% NaCl solution of $\mathrm{Mg}$ alloys NZ30K and AZ91D, Journal of Applied Electrochemistry 38 (2008) 207.

15. Ágnes Csanády, Dénes Marton, Stress corrosion behaviour of Al-Zn-Mg alloys based upon microchemical surface reactions, Journal of Material Science 14 (1979) 2289.

16. F. Witte, V. Kaese, H. Haferkamp, E. Switzer, A. Meyer-Lindenberg, C.J. Wirth, H. Windhagen, In vivo corrosion of four magnesium alloys and the associated bone response, Biomaterials 26 (2005) 3557.

17. Ming Zhao, Shusen Wu, Ping An, Jirong Luo, Y. Fukuda, H. Nakae, Microstructure and corrosion resistance of a chromium-free multi-elements complex coating on AZ91D magnesium alloy, Materials Chemistry and Physics 99 (2006) 54.

18. S. Bender, J. Goellner, A. Heyn, E. Boese, Corrosion and corrosion testing of magnesium alloys, Materials and Corrosion 58 (2007) 977.

19. Michiaki Yamasaki, Naoyuki Hayashia, Shogo Izumia, Yoshihito Kawamuraa, Corrosion behavior of rapidly solidified Mg-Zn-rare earth element alloys in $\mathrm{NaCl}$ solution, Corrosion Science 49 (2007) 255.

20. Chenglong Liu, Yunchang Xin, Corrosion resistance of titanium ion implanted AZ91 magnesium alloy, Journal of Vacuum Science and Technology A 25 (2007) 334.

21. Roy L. Petty, Arthur W. Davidson, Jacob Kleinberg, The anodic oxidation of magnesium metal: Evidence for the existence of unipositive magnesium, Journal of the American Chemical Society 76 (1954) 363-366.

22. M. Garreau, P.L. Bonora, On the role of the anions on the anomalous anodic dissolution of aluminium, Journal of Applied Electrochemistry 7 (1977) $197-209$

23. John O’M Bockris, Shahed U.M. Khan, Quantum Electrochemistry, vol. 48, Plenum Press, New York and London, 1979.

24. J.O'M. Bockris, Modern Aspects of Electrochemistry, vol. 1, Butterworth, London, 1954. p. 236.

25. R.A. Marcus, On the theory of electron-transfer reactions. VI. Unified treatment for homogeneous and electrode reactions, Journal of Chemical Physics 43 (1965) 679.

26. J.O'M. Bockris, D.B. Matthews, The mechanism of charge transfer at electrodes, Proceedings of the Royal Society A 292 (1966) 479.

27. Henry H. Bauer, The electrochemical transfer-coefficient, Journal of Electroanalytical Chemistry 16 (1968) 419.

28. Jean-Michel Savéant, Didier Tessier, Variation of the electrochemical transfer coefficient with potential, Faraday Discussions of the Chemical Society 74 (1982) 57. 